\title{
○ Rice
}

a SpringerOpen Journal

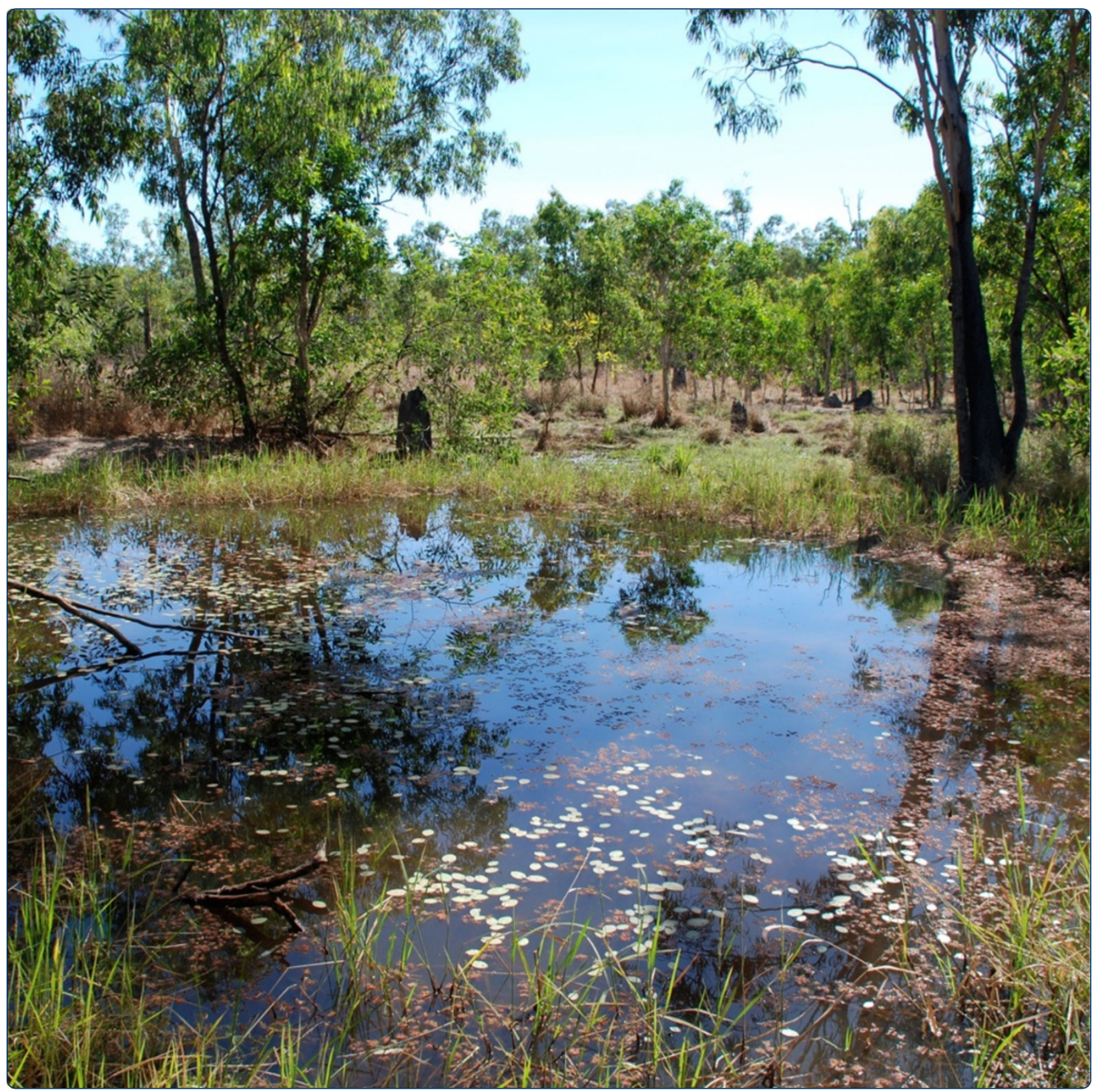

\section{Molecular relationships between Australian annual wild rice, Oryza meridionalis, and two related perennial forms}

Sotowa et al. 


\title{
Molecular relationships between Australian annual wild rice, Oryza meridionalis, and two related perennial forms
}

Masahiro Sotowa ${ }^{1}$, Kenta Ootsuka ${ }^{1}$, Yuu Kobayashi ${ }^{1}$, Yin $\mathrm{Hao}^{2}$, Katsunori Tanaka ${ }^{3}$, Katsuyuki Ichitani ${ }^{4}$, Jonathan M Flowers ${ }^{5}$, Michael D Purugganan ${ }^{5}$, Ikuo Nakamura ${ }^{6}$, Yo-Ichiro Sato ${ }^{7}$, Tadashi Sato $^{8}$, Darren Crayn ${ }^{9}$, Bryan Simon ${ }^{10}$, Daniel LE Waters ${ }^{11}$, Robert J Henry ${ }^{12}$ and Ryuji Ishikawa ${ }^{1 *}$

\begin{abstract}
Background: The perennial, Oryza rufipogon distributed from Asia to Australia and the annual O. meridionalis indigenous to Australia are AA genome species in the Oryza. However, recent research has demonstrated that the Australian AA genome perennial populations have maternal genomes more closely related to those of $O$. meridionalis than to those found in Asian populations of $O$. rufipogon suggesting that the Australian perennials may represent a new distinct gene pool for rice.
\end{abstract}

Results: Analysis of an Oryza core collection covering AA genome species from Asia to Oceania revealed that some Oceania perennials had organellar genomes closely related to that of $O$ meridionalis (meridionalis-type). O. rufipogon accessions from New Guinea carried either the meridionalis-type or rufirpogon-type (like O. rufipogon) organellar genomes. Australian perennials carried only the meridionalis-type organellar genomes when accompanied by the rufipogon-type nuclear genome. New accessions were collected to better characterize the Australian perennials, and their life histories (annual or perennial) were confirmed by field observations. All of the material collected carried only meridionalis-type organellar genomes. However, there were two distinct perennial groups. One of them carried an rufipogon-type nuclear genome similar to the Australian O. rufipogon in the core collection and the other carried an meridionalis-type nuclear genome not represented in the existing collection. Morphologically the rufipogon-type shared similarity with Asian $O$. rufipogon. The meridionalis-type showed some similarities to $O$. meridionalis such as the short anthers usually characteristic of annual populations. However, the meridionalis-type perennial was readily distinguished from $O$. meridionalis by the presence of a larger lemma and higher number of spikelets.

Conclusion: Analysis of current accessions clearly indicated that there are two distinct types of Australian perennials. Both of them differed genetically from Asian $O$. rufipogon. One lineage is closely related to $O$. meridionalis and another to Asian 0 . rufipogon. The first was presumed to have evolved by divergence from $O$. meridionalis becoming differentiated as a perennial species in Australia indicating that it represents a new gene pool. The second, apparently derived from Asian O. rufipogon, possibly arrived in Australia later.

Keywords: Genetic divergence; Australia; Perennial; Annual; Oryza rufipogon; Oryza meridionalis

\footnotetext{
* Correspondence: ishikawa@cc.hirosaki-u.ac.jp

${ }^{1}$ Faculty of Agriculture and Life Science, Hirosaki University, Hirosaki, Aomori 036-8561, Japan

Full list of author information is available at the end of the article
}

\section{实 Springer}

(c) 2013 Sotowa et al.; licensee Springer. This is an open access article distributed under the terms of the Creative Commons Attribution License (http://creativecommons.org/licenses/by/2.0), which permits unrestricted use, distribution, and reproduction in any medium, provided the original work is properly cited. 


\section{Background}

Oryza rufipogon is the recognized wild progenitor of cultivated rice, Oryza sativa, and is generally presumed to be distributed from Asia to Australia (Chang 1976, Vaughan 1994). Both annual and perennial forms of wild rice are found in Australia. The perennial form has been regarded as $O$. rufipogon, while the annual form is $O$. meridionalis. The classification of Oryza species has been reviewed by Oka (1988). Two species, O. sativa and O. glaberrima, are known to be domesticated forms. These cultigens have been domesticated from AA genome species within the genus Oryza. O. sativa was domesticated originally in Asia and thereafter spread widely as a major crop. O. glaberrima was domesticated in western tropical Africa with restricted usage. The evolution of the genus Oryza, especially the AA genome species, has been a topic of considerable research interest. These species are widely distributed globally and were once regarded as the $O$. perennis complex consisting of geographical races Asian, African, American, and Oceanian - inhabiting different regions (Morishima 1969). These were subsequently renamed and divided into different species: $O$. rufipogon, O. barthii, O. longistaminata, O. glumaepatula, and $O$. meridionalis (Oka 1988). The wild progenitor of $O$. glaberrima is an annual species, O. barthii, widespread in west tropical Africa. The related perennial species, $O$. longistaminata, is more widely distributed in Africa. $O$. glumaepatula is a perennial species in South America, known as floating rice. The culms may break at internodes and the floating fragmented stems have the capability to regenerate shoots and roots (Akimoto et al. 1998). O. meridionalis is a species endemic to Oceania including New Guinea and Australia, characterized by an annual life history and morphologically by a short anther length (Ng et al. 1981, Vaughan 1994, Lu 1999). O. rufipogon is distributed from Asia to Australia and demonstrates a wide range of life history traits from annual to perennial (Oka and Morishima 1967, Vaughan 1994). The annual form is sometimes referred to as a distinct species, $O$. nivara, which is spread over a wide area from the Deccan Peninsula to the Gangetic valley. Other researchers regard this species as an annual form of O. rufipogon (Oka 1974, Sharma 2003). This divergence between annual and perennial types within a single species is found only in $O$. rufipogon. Two species in Africa correspond to these life histories. As O. meridionalis from Oceania is regarded as an annual species, taxonomists have defined perennials from that region as O. rufipogon (Henry et al. 2010).

Divergence of annual-perennial life history traits has been centered on reproductive systems and longevity. Annuals produce more abundant seeds than perennials before the plants die. In contrast, perennials preferentially propagate vegetatively. O. meridionalis grows during the rainy season and dies in the dry season after shedding seeds. This life history trait is the same as that of the annual form of $O$. rufipogon. Perennials are also found in Australia in and around relatively large ponds where water is available continuously throughout the seasons. Sometimes annuals and perennials grow together in the rainy season, usually until around late April. Later, only the perennials remain and propagate vegetatively.

In general, perennials are characterized not only by high vegetative reproduction performance but also marked ability for competitive growth, late flowering, and high outcrossing rates (Sano and Morishima 1982, Morishima et al. 1984). Alternative resource allocations found in annuals result in a low ability to regenerate shoots from nodes, high seed productivity, and short anthers (Oka 1988, Oka and Morishima 1967). These trends for differing resource allocations are generally found among different AA genome species and intermediate types have been found in Oryza rufipogon (Sano and Morishima 1982).

The distribution of O. rufipogon is known to range from Asia to Australia beyond the biogeographical boundary known as the Wallace line (Wallace 1880, Vaughan 1994). In contrast, the distribution of $O$. meridionalis is restricted and endemic to Oceania. The Wallace line separates the edges of the ancient continents, Sunda (the expanded Eurasian continent including Malaysia) and Saful (the united landmasses of New Guinea, Australia, and Tasmania). It is known that fauna and flora have crossed this line for dispersal. Some fauna migrated across the line when sea levels became lower at the last Glacial Maximum. For example, humans migrated across this line 50,000 70,000 years ago, when presumably they had not yet acquired agriculture (Bellwood 2005). Flora and fauna have migrated between Asia and Australia over an extended period (Augee and Fox 2012).

Gondwanan elements radiated lineages to form endemic species in Australia. However, more recent immigration from Asia was also extensive. In the fauna, two lizard groups (varanids and gekkonnids) and elapid snakes are known as early immigrants to Australia from South-East Asia. Later immigrants in the mid Tertiary include lizards (scincids and agamids), snakes (typhlopids, boids and acrochorbids), and crocodiles of the genus Crocodylus, all of which have close links with South-East Asia. Some frogs, pitted-shelled turtles, snakes and herbivorous bats are relatively recent arrivals as Quaternary immigrants. Plants can move from place to place being spread by wind or by animal vectors. Many tropical plants have moved between South-east Asia and northern Australia. Endemic species in Australia constitute only 14\% of the flora in the tropical zone of Australia compared with 47\% in the temperate zone in Australia (Augee and Fox 2012). Wild rice, O. rufipogon, might have expanded its distribution from Asia to Australia spontaneously or been accidentally 
transported by animals including humans or birds. This may have happened after the progenitor of $O$. meridionalis had reached Australia, as molecular divergence indicates that $O$. meridionalis diverged from O. rufipogon 0.4 to 2 million years ago, long before rice had been domesticated and a dispersal of $O$. rufipogon to the Australian continent (Zhu and Ge 2005, Tang et al. 2010).

Genetic comparison of isozymes among Asian, Oceanian, American, and African forms of AA genome species indicates that the American form, O. glumaepatula, is most closely related to the Asian form; the African form is the next closest, and the most distant form is the annual Oceanian form, O. meridionalis (Second 1985). Thus, it is difficult to obtain fertile progeny by crossing between Asian $O$. rufipogon and the Australian endemic species $O$. meridionalis (Chu et al. 1969). Nucleotide sequences of particular genes suggest that $O$. meridionalis and O. longistaminata have the longest divergence from $O$. rufipogon among the AA genome species (Ge et al. 1999, Cheng et al. 2002, Takahashi et al. 2008). If Australian perennials belong to O. rufipogon, they may have resulted from a recent introgression from Asia to Australia, or they represent an independent lineage related to the endemic species, O. meridionalis because of their distinct ecological habitats. Complete chloroplast genomes including Asian and Australian perennials have recently been reported (Waters et al. 2012). The chloroplast DNA (ctDNA) of the Australian perennial shares a higher similarity with $O$. meridionalis. This was reconfirmed in this study by analysis of the National Institute of Genetics at Mishima, Japan (NIG) core collection (hereafter, core collection), from which representative accessions were selected and established in a National Bio-Resource Project (NBRP) of Japan. The collection has 1,701 wild rice accessions of 20 species of the genus Oryza. Representative accessions of each species have been selected as a core collection representing the typical variation in wild rice (Nonomura et al. 2010). The core collection includes 39 O. rufipogon throughout Asia to Oceania with 32 of them originated from Asia, five from New Guinea, and two from Australia. They were regarded as perennials based on their passport data. In addition to the ex situ collection, we have worked to collect and evaluate wild rice in situ as a new collection which could be accessed to confirm environmental conditions and population structure further. By using the core collection and the new accessions, we have now conducted further detailed characterization of the nuclear genomes of Australian perennials and the relationships between chloroplast DNA (ctDNA), mitochondorial DNA (mtDNA), and nuclear DNA to determine the precise distribution of Asian O. rufipogon and to evaluate the unique genetic resources endemic to Australia. In this report, we identified two alternative types of perennial accessions at the morphological and molecular levels in Australia. Both of them were highly divergent from Asian O. rufipogon at the organellar DNA (including both ctDNA and mtDNA) level and they showed different morphological and nuclear DNA characteristics from each other. One of the perennial types was referred to as O. rufipogon, r-type, perennial and is similar to Asian O. rufipogon at the nuclear DNA level. Another type was referred to as an O. meridionalis, $\mathrm{m}$-type, perennial and is similar to O. meridionalis. We characterized their divergent traits and described these new gene pools in a study that should prove useful in understanding rice evolution and to support genetic improvement of modern cultivars.

\section{Results}

\section{Newly collected accessions}

Newly collected accessions were collected from north Queensland, Australia at the beginning of the dry season (Figure 1a). These accessions were distinctive from other accessions because they were characterized with the detailed ecological features of each site and with Global Positioning System (GPS) data. Thus, we have referred to them as new accessions to distinguish them from the past accessions. All accessions were named by site name (for example Jpn1). Multiple samples were collected and stocked at the DNA bank at Southern Cross University, New South wales, Australia under approval of EcoAccess published by the Queensland state government. Annual individuals were collected at Jpn6, Jpn7, Jpn8, Jpn9, and P27 (Table 1, Figure 1a, c). In contrast, living individuals were collected at Jpn1, Jpn2, Jpn3, Jpn4, Jpn10, and Jpn11 where perennial populations were found as confirmed by our repetitive observations. The Jpn1 population lives in a swamp (Figure 1d-f), and in the dry season, the swamp was still muddy with some moisture at August (Figure 1d). These conditions are sufficient for perennial vegetation to survive. Panicle morphology clearly showed that they were distinct from $O$. meridionalis. The Jpn2 site was far from the Jpn1 site and located on the Great Dividing Range (Figure 1a). The site was an isolated small pond as shown in Figure 1g-i. In the dry season, there was still plenty of water to support perennial individuals (Figure 1i). The perennial wild rice individuals were found around the pond but not in the central part. This suggested that they have a different strategy to adapt to water condition compared with floating rice. Gradually the water area shrunk in the dry season (Figure 1i). Other details were listed in Table 1. Accessions at the P27 site were classified in this study as $O$. meridionalis, because they behaved as annual wild rice. They did not survive in the greenhouse after flowering.

\section{Divergent plastid sequences in Australian samples}

Sequences of chloroplast protein coding gene, rpl16 which includes one intron, were compared within the 


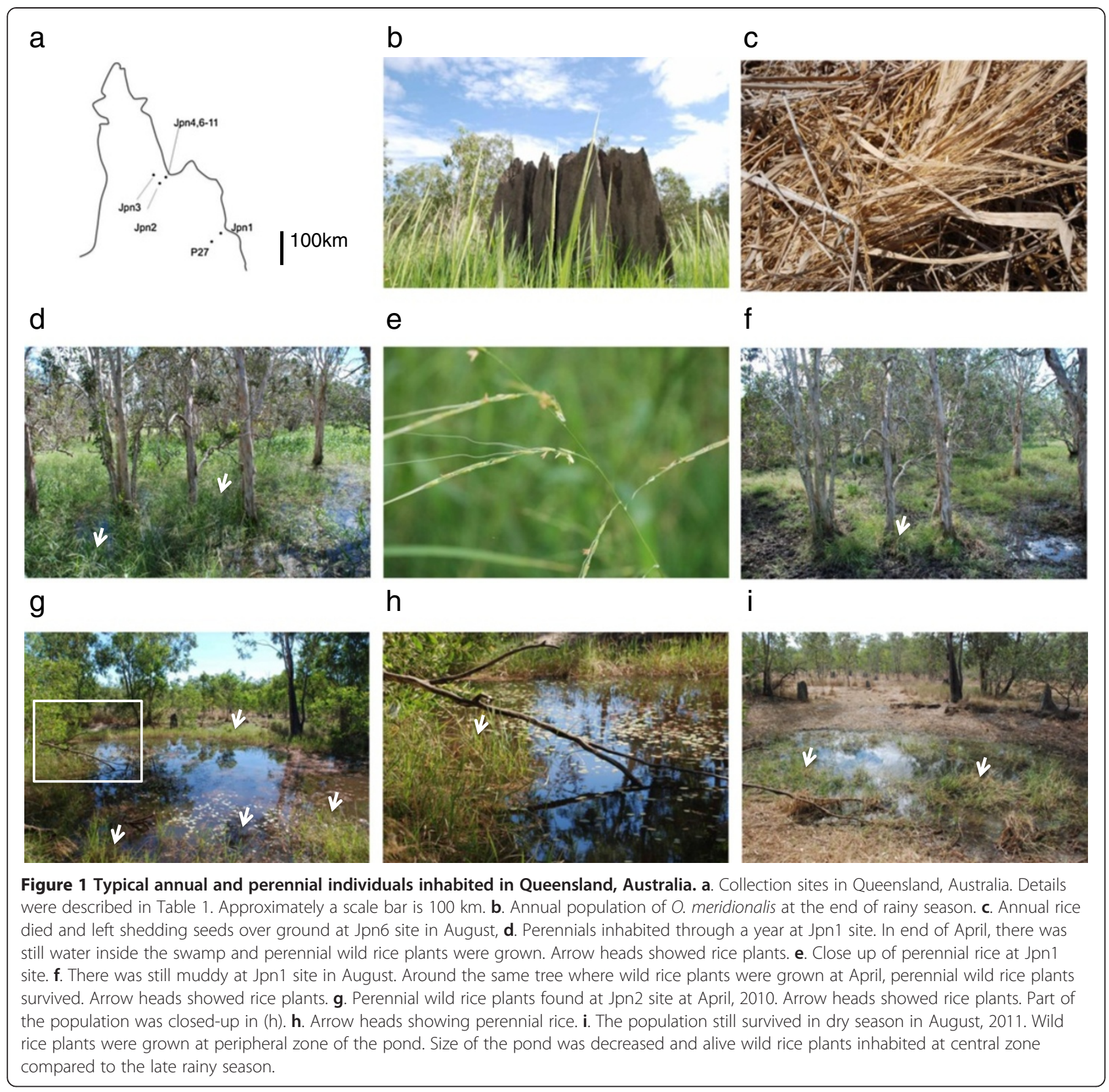

Oryza core collection (Table 2, Additional file 1: Figure S1). SNPs and a $C$ nucleotide insertion were detected as polymorphic sites. The $\mathrm{C}$-nucleotide insertion between 770/771-nt in the gene was found in three out of five New Guinean accessions, two Australian O. rufipogon, and 18 O. meridionalis (Figure 2).

This insertion represents a distinct difference between Asian O. rufipogon and Oceanian wild rice including some New Guinean O. rufipogon, Australian O. rufipogon, and O. meridionalis. Thus, hereafter the latter type was termed merdionalis- type.

The ORF100-INDEL previous reported as a 5 bp insertion or two $5 \mathrm{bp}$ insertions in O. meridionalis was also genotyped. These insertions were always associated with the $C$ insertion (Table 3). Most of the Oceania accessions carried one of the two 5 bp INDELs, while W1631 and W2071 carried two 5 bp insertions (Additional file 1: Figure $\mathrm{S} 1$ ). The remaining $O$. meridionalis accessions carried a single insertion between nucleotide 7998 and nucleotide 7999 in the ctDNA. Thus, it was possible to characterize all of the Australian accessions including Australian O. rufipogon and $O$. meridionalis by the $\mathrm{C}$ insertion with the ORF100-INDEL when the core-collection was used.

In addition, three SNPs in rpl16 divided accessions into sub-clades within the species. A $\mathrm{C}$ to $\mathrm{T}(\mathrm{C}-\mathrm{T})$ nucleotide 
Table 1 Core collection from national bio- resources in National Institute of Genetics and new collection

\begin{tabular}{|c|c|c|c|}
\hline Acc. no. & No of individuals & Species or life history & Origin \\
\hline \multicolumn{4}{|c|}{ National bio-resource project, core collection } \\
\hline W1297 & 1 & O. meredionalis & Darwin, Australia \\
\hline W1300 & 1 & O. meredionalis & Darwin, Australia \\
\hline W1625 & 1 & O. meredionalis & Darwin, Australia \\
\hline W1627 & 1 & O. meredionalis & Australia \\
\hline W1631 & 1 & O. meredionalis & Kununurra area, Australia \\
\hline W1635 & 1 & O. meredionalis & Darwin, Australia \\
\hline W1638 & 1 & O. meredionalis & Queensland, Australia \\
\hline W2069 & 1 & O. meredionalis & Kununurra area, Australia \\
\hline W2071 & 1 & O. meredionalis & Kununurra area, Australia \\
\hline W2077 & 1 & O. meredionalis & from Darwin to Normanton, Australia \\
\hline W2079 & 1 & O. meredionalis & from Darwin to Normanton, Australia \\
\hline W2080 & 1 & O. meredionalis & from Darwin to Normanton, Australia \\
\hline W2081 & 1 & O. meredionalis & Matarauka, Australia \\
\hline W2100 & 1 & O. meredionalis & Queensland, Australia \\
\hline W2103 & 1 & O. meredionalis & Queensland, Australia \\
\hline W2105 & 1 & O. meredionalis & Queensland, Australia \\
\hline W2112 & 1 & O. meredionalis & Queensland, Australia \\
\hline W2116 & 1 & O. meredionalis & Queensland, Weipa, North Point, Australia \\
\hline \multicolumn{4}{|c|}{ Asian O. rufipogon } \\
\hline W0106 & 1 & O. rufipogon & Phulankara, near Cuttack, Orissa, India \\
\hline W0107 & 1 & O. rufipogon & Pahala, Orissa, India \\
\hline W0108 & 1 & O. rufipogon & Cuttack, Orissa, India \\
\hline W0120 & 1 & O. rufipogon & Cuttack, Orissa, India \\
\hline W0137 & 1 & O. rufipogon & Kadiam, Andhra, India \\
\hline W0180 & 1 & O. rufipogon & Ngao, Lampang, Thailand \\
\hline W0593 & 1 & O. rufipogon & Binjai, Rendah, Malaya \\
\hline W0610 & 1 & O. rufipogon & Rangoon, Burma \\
\hline W0630 & 1 & O. rufipogon & Magwe, Burma \\
\hline W1294 & 1 & O. rufipogon & Musuan, Mindanao Philippines \\
\hline W1551 & 1 & O. rufipogon & Saraburi, Thailand \\
\hline W1666 & 1 & O. rufipogon & Siliguri, India \\
\hline W1669 & 1 & O. rufipogon & Orissa, India \\
\hline W1681 & 1 & O. rufipogon & Orissa, India \\
\hline W1685 & 1 & O. rufipogon & Orissa, India \\
\hline W1690 & 1 & O. rufipogon & Chengrai, Thailand \\
\hline W1715 & 1 & O. rufipogon & China \\
\hline W1807 & 1 & O. rufipogon & Sri Lanka \\
\hline W1852 & 1 & O. rufipogon & Chiang Saen, Thailand \\
\hline W1865 & 1 & O. rufipogon & Saraburi, Thailand \\
\hline W1866 & 1 & O. rufipogon & Saraburi, Thailand \\
\hline W1921 & 1 & O. rufipogon & Saraburi, Thailand \\
\hline
\end{tabular}

National bio-resource project, core collection 


\section{Table 1 Core collection from national bio- resources in National Institute of Genetics and new collection (Continued)}

\begin{tabular}{|c|c|c|c|c|}
\hline W1939 & 1 & O. rufipogon & \multicolumn{2}{|l|}{ Bangkoknoi, Thailand } \\
\hline W1945 & 1 & O. rufipogon & \multicolumn{2}{|l|}{ No description } \\
\hline W1981 & 1 & O. rufipogon & \multicolumn{2}{|l|}{ Palembang Indonesia } \\
\hline W2003 & 1 & O. rufipogon & \multicolumn{2}{|l|}{ from Pajani to Bombay, Indai } \\
\hline W2014 & 1 & O. rufipogon & \multicolumn{2}{|l|}{ India } \\
\hline W2051 & 1 & O. rufipogon & \multicolumn{2}{|l|}{ Hobiganji, Bangladesh } \\
\hline W2263 & 1 & O. rufipogon & \multicolumn{2}{|l|}{ Cambodia } \\
\hline W2265 & 1 & O. rufipogon & \multicolumn{2}{|l|}{ Laos } \\
\hline W2266 & 1 & O. rufipogon & \multicolumn{2}{|l|}{ Laos } \\
\hline W2267 & 1 & O. rufipogon & \multicolumn{2}{|l|}{ Laos } \\
\hline \multicolumn{5}{|c|}{ Australian O. rufipogon } \\
\hline W2078 & 1 & O. rufipogon & \multicolumn{2}{|l|}{ from Darwin to Normaton, Australia } \\
\hline W2109 & 1 & O. rufipogon & \multicolumn{2}{|l|}{ Queensland, Australia } \\
\hline \multicolumn{5}{|c|}{ New Guinean O. rufipogon } \\
\hline W1230 & 1 & \multicolumn{2}{|l|}{ O. rufipogon } & $\begin{array}{l}\text { Baad, Koembe, Ducth New Guinea, collected } \\
\text { by Katayama (1968) O. perrenis }\end{array}$ \\
\hline W1235 & 1 & \multicolumn{2}{|l|}{ O. rufipogon } & $\begin{array}{l}\text { Baad, Koembe, Ducth New Guinea, collected } \\
\text { by Katayama (1968) O. sativa var. spontanea* }\end{array}$ \\
\hline W1236 & 1 & \multicolumn{2}{|l|}{ O. rufipogon } & $\begin{array}{l}\text { Baad, Koembe, Ducth New Guinea, collected } \\
\text { by Katayama (1968) O. perrenis }\end{array}$ \\
\hline W1238 & 1 & \multicolumn{2}{|l|}{ O. rufipogon } & $\begin{array}{l}\text { Baad, Koembe, Ducth New Guinea, collected } \\
\text { by Katayama (1968) O. sativa var. spontanea }\end{array}$ \\
\hline W1239 & 1 & \multicolumn{2}{|l|}{ O. rufipogon } & $\begin{array}{l}\text { Baad, Koembe, Ducth New Guinea, collected } \\
\text { by Katayama (1968) O. sativa var. spontanea }\end{array}$ \\
\hline \multicolumn{2}{|c|}{ New collection } & (Life history) & & \\
\hline Jpn1 & 3 & Perennial & \multicolumn{2}{|l|}{ Queensland, Australia (S16.38.085, E145.19.366) } \\
\hline Jpn2 & 5 & Perennial & \multicolumn{2}{|l|}{ Queensland, Australia (S15.26.219, E114.12.397) } \\
\hline Jpn3 & 5 & Perennial & \multicolumn{2}{|l|}{ Queensland, Australia (S15.04.306, E143.43.212) } \\
\hline Jpn4 & 3 & Perennial & \multicolumn{2}{|l|}{ Queensland, Australia (S14.48.481, E143.20.209) } \\
\hline Jpn6 & - & Annual & \multicolumn{2}{|l|}{ Queensland, Australia (S14.36.294, E143.55.490) } \\
\hline Jpn7 & - & Annual & \multicolumn{2}{|l|}{ Queensland, Australia (S14.42.318, E144.00.130) } \\
\hline Jpn8 & - & Annual & \multicolumn{2}{|l|}{ Queensland, Australia (S14.45.458, E144.04.409) } \\
\hline Jpn9 & - & Annual & \multicolumn{2}{|l|}{ Queensland, Australia (S14.44.229, E144.04.111) } \\
\hline Jpn10 & 4 & Perennial & \multicolumn{2}{|l|}{ Queensland, Australia (S14.45.244, E144.07.160) } \\
\hline Jpn11 & 3 & Perennial & \multicolumn{2}{|l|}{ Queensland, Australia (S14.50.582, E144.10.055) } \\
\hline P27 & 8 & O. meridionalis & \multicolumn{2}{|l|}{ Mareeba (S16.55.02, E145.232.312) } \\
\hline
\end{tabular}

O. sativa var. spontanea which is identical to $O$. nivara, probably a form of $O$. rufipogon.

substitution at nucleotide 1406 was found in 25 out of 32 Asian O. rufipogon accessions (Figure 2, Additional file 1: Figure S1). Two substitutions, T-A at nucleotide 676 and $\mathrm{C}-\mathrm{T}$ at nucleotide 1296, divided O. meridionalis into three sub-clades. The latter predominated in accessions originating from Queensland. The A stretches beside the $\mathrm{C}$ insertion varied from 11 to 19 repeats in total, while $O$. meridionalis showed only three types of A stretches, referred to as 11A, 14A, and 15A (Table 3). In O. meridionalis, W2081 carried the 11A type, and three accessions - W1635, W2071, and W2077 - carried the 15A type.
Two Asutralian O. rufipogon accessions, W2078 and W2109 and three New Guinean O. rufipogon accessions, W1235, W1238, and W1239, carried 15A and 14A, respectively, all of which were characterized by the $C$ insertion. Another two New Guinean O. rufipogon accessions, W1230 and W1236 carried different repeats, 17A and 16A, respectively, both of which did not carry the $\mathrm{C}$ insertion. The meridionalis-type $O$. rufipogon accessions in Oceania carried A-stretches within the variation found in O. meridionalis.

An INDEL detected in mtDNA was also found to parallel with ctDNA polymorphism (Figure 3, Table 3). Three 
Table 2 Primers used to detect INDEL and SSR

\begin{tabular}{|c|c|c|c|c|c|}
\hline Primer name & Chr & Genome position (nt) & Forward primer $\left(5^{\prime}-3^{\prime}\right)$ & Reverse primer $\left(5^{\prime}-3^{\prime}\right)$ & Remarks (O. meridionalisis) \\
\hline rp116 & & & AGAAATTCTACCTCTITCTATAAG & AATTGCCTCGGTAGGATTTTCC & \\
\hline ORF100-INDEL & & & GCCGCTTTAGTCCACTCAGCCATC & TCAATGCCTIIITTCAATGGTCTC & 5 bp insert \\
\hline ctDNA336 & & & ACAGAGGCAAGAAATAACGATTG & TTATTCTTTCTTTCCAATTTTATG & For genotyping of ctDNA insertions \\
\hline mtDNA indel & & & GACTCTGATTCCCCCACTATGAGAGAGCTG & CAGTCCGATGCGTTTGAGCAGTAG] & 4,132 bp deletion \\
\hline INDEL5 & chr10 & 20772383 & AAGTGTGCCTTGCAACCGAG & AAGCAGCAGAACACCTGAAAC & 20 bp deletion \\
\hline INDEL7 & chr10 & 21653822 & GTAGCTAGTCGACAGGCAGATG & TACTGGGTATGTAAACCTGCAC & 92 bp deletion \\
\hline INDEL8 & chr5 & 25412945 & GATATATTTGTGCTGGCATTCTC & TTCCAGTGAAAATCATATGCAC & 33 bp deletion \\
\hline INDEL9 & chr6 & 28288641 & GTGTTCCTAAAACTTATGCATTGTG & CTACCAATTAGCTGTATTAACAAG & $60 \mathrm{bp}$ deletion \\
\hline INDEL10 & chr3 & 32263786 & ATTCAACAGCAGAATGGATTTC & GAGCAGTTATAGTAACTTGGAGG & 155 bp deletion \\
\hline SSR1 & chr3 & 10541915 & GCCACCGAAACTTGTACCGTC & GTAACTITCTGGTTGTTCCTAAAC & SSR \\
\hline SSR2 & chr6 & 13061135 & CTCCACCGTGAATGTACGTAAG & CGCATCACCTCCTGCAAC & SSR \\
\hline SSR3 & chr10 & 21872477 & CAAAGCTAGCCACTTGCATATG & GTCGTCGACGAACTTGGATAG & SSR \\
\hline SSR5 & chr4 & 27568462 & CTTGTCAACTACTGTGGCAAG & AGAAGATCAACGGTGGTATAG & SSR \\
\hline SSR7 & chr10 & 15561422 & CAAGGATGCTATAAGAGCAAAAAC & TCCTAACACTCCTATTTCATC & SSR \\
\hline SSR9 & chr5 & 1913 & CTGCAAGGATCGCAAACAAAG & TATGGAAATTTGTGCGAGGTG & SSR \\
\hline SSR15 & chr3 & 34182494 & CCTTGGTATTGGTTTGAATIG & TAAAGGATTGCTGGAGAAAGAAG & SSR \\
\hline
\end{tabular}




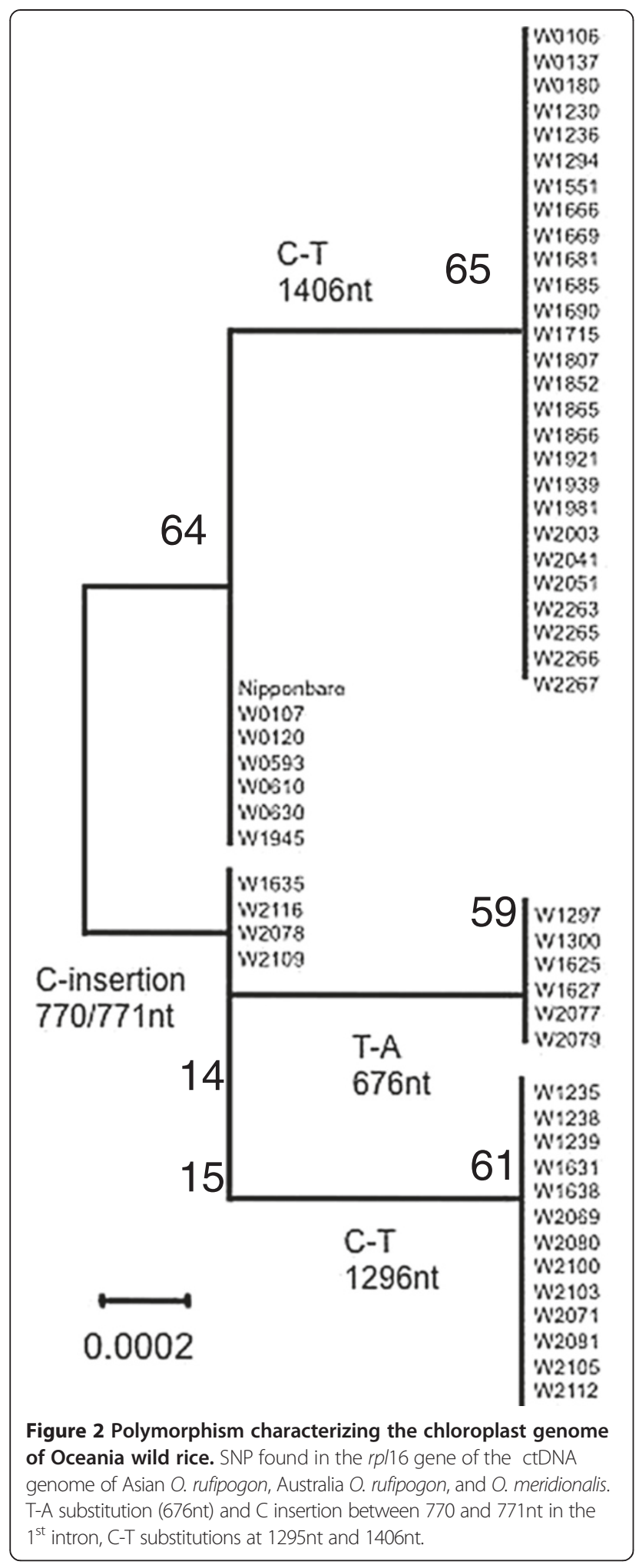

New Guinean accessions, W1235, W1238, and W1239, carried the meridionalis-type ctDNA polymorphism and had the same mtDNA deletion type as Australian O. rufipogon and $O$. meridionalis but the remaining accessions shared similar genomes with Asian O. rufipogon.

All perennial accessions in Australia carried the $C$ insertion in rpl16 along with the insertion in the ORF100INDEL and the deletion in mtDNA. It was concluded that all Australian perennials carried the meridionalis-type organellar genomes. New Guinean O. rufipogon accessions carried either type, rufipogon- or meridionalis-type. The New Guinean accessions were collected in 1960' (Katayama 1968). Two of them, W1230 and W1236 were defined as O. perennis (regarded as current perennial type O. rufipogon) and others were as O. sativa var. spontanea (current annual type $O$. rufipogon or O. nivara). As the ecological habit in nature is not certain at present without GPS data, new accessions were further characterized with ecological information to characterize perennial accessions in Australia.

\section{Genotyping of nuclear DNA}

Nuclear INDEL markers were designed to distinguish $O$. meridionalis from Nipponbare (Additional file 2: Figure S2). The 32 Asian O. rufipogon accessions all carried insertions at the five loci (Table 4). In contrast, the $18 \mathrm{O}$. meridionalis accessions carried deletions at all loci compared to Nipponbare and other Asian O. rufipogon. The genotypes with the deletions were defined as having the meridionalis-type nuclear genome. These INDELs were able to strictly distinguish the rufipogon-type from the meridionalis-type nuclear genomes except for INDEL10. This insertion was homologous with a Stoway DNA transposon and one Australian accession in the core collection showed the deletion type. However, other accessions regarded as O. rufipogon had the insertion. These INDELs were used to characterize the Australian perennials.

The new perennial accessions, except for those from the Jpn1 site, showed deletions at the five loci. They were genetically similar to O. meridionalis at the nuclear DNA level, even though this species is known to be an annual, and the collected accessions were all perennial. However, three accessions at the Jpn1 site showed genotypes without the deletion at all loci like Asian O. rufipogon, although they carried the meridionalis-type organellar genomes. Their nuclear genomes were determined to be rufipogon-type. This suggested that the Jpn1 accessions were genetically similar to O. rufipogon at the nuclear DNA level, although they shared the same meridionalis-type organella genome as the other Australian perennials. Thus, it was concluded that there are different perennial types in Australia, r-type and m-type. The former carries rufipogontype nuclear genome and meridionalis-type organelle genomes. The latter carries all meridionalis-type including both nuclear and organelle genomes. Both r-type and m- 
Table 3 Variation at ctDNA and mtDNA polymorphism

\begin{tabular}{|c|c|c|c|c|c|c|c|c|c|c|c|c|c|c|c|}
\hline \multirow{3}{*}{ Site/Collection } & \multirow{3}{*}{ Species/Accession } & \multirow{3}{*}{$\begin{array}{l}\text { No. of } \\
\text { strains }\end{array}$} & \multicolumn{8}{|c|}{ Variation of stretches } & \multicolumn{3}{|c|}{ ORF 100-INDEL } & \multicolumn{2}{|c|}{ mtDNA-INDEL } \\
\hline & & & \multicolumn{5}{|c|}{ C-absence } & \multicolumn{3}{|c|}{ C-presence } & \multirow{2}{*}{-} & \multicolumn{2}{|c|}{+} & \multirow[t]{2}{*}{-} & \multirow[t]{2}{*}{+} \\
\hline & & & $15 \mathrm{~A}$ & $16 A$ & $17 \mathrm{~A}$ & $18 \mathrm{~A}$ & $19 A$ & $11 \mathrm{~A}$ & $14 \mathrm{~A}$ & $15 A$ & & $+5 \mathrm{bp}$ & $+10 \mathrm{bp}$ & & \\
\hline Jpn 1 & Australian perennial accesison & 3 & 0 & 0 & 0 & 0 & 0 & 0 & 0 & 3 & 0 & 3 & 0 & 3 & 0 \\
\hline Jpn 2 & Australian perennial accesison & 5 & 0 & 0 & 0 & 0 & 0 & 0 & 0 & 5 & 0 & 5 & 0 & 5 & 0 \\
\hline Jpn 3 & Australian perennial accesison & 5 & 0 & 0 & 0 & 0 & 0 & 0 & 0 & 5 & 0 & 5 & 0 & 5 & 0 \\
\hline Jpn 4 & Australian perennial accesison & 3 & 0 & 0 & 0 & 0 & 0 & 0 & 0 & 3 & 0 & 3 & 0 & 3 & 0 \\
\hline Jpn 10 & Australian perennial accesison & 3 & 0 & 0 & 0 & 0 & 0 & 0 & 0 & 3 & 0 & 3 & 0 & 3 & 0 \\
\hline Jpn 11 & Australian perennial accesison & 3 & 0 & 0 & 0 & 0 & 0 & 0 & 0 & 3 & 0 & 3 & 0 & 3 & 0 \\
\hline Core collection & O. meridionalis & 18 & 0 & 0 & 0 & 0 & 0 & 1 & 14 & 3 & 0 & 16 & 2 & 18 & 0 \\
\hline Core collection & Asian O. rufipogon & 32 & 6 & 8 & 15 & 2 & 1 & 0 & 0 & 0 & 32 & 0 & 0 & 0 & 32 \\
\hline Core collection & Australian O. rufipogon & 2 & 0 & 0 & 0 & 0 & 0 & 0 & 0 & 2 & 0 & 2 & 0 & 2 & 0 \\
\hline Core collection & New Guinean O. rufipogon & 5 & 0 & 1 & 1 & 0 & 0 & 0 & 3 & 0 & 2 & 3 & 0 & 3 & 2 \\
\hline
\end{tabular}

Adenine stretches beside the $\mathrm{C}$ insertion in $r p 116$, nucleotide in 1st intron of $r p 116$ and INDEL in mtDNA.

type carried meridionalis-type organelle genomes demonstrating their divergence from Asian O. rufipogon.

Seven SSR loci were used to compare species diversity and phylogenetic relationships among Asian O. rufipogon, O. meridionalis, New Guinean O. rufipogon, and Australian perennials (Table 5). Fst scores for the seven loci ranged from 0.21 to 0.80 (mean $\pm S D, 0.53 \pm 0.09$ ). They did not diverge as much as the nuclear INDEL markers ( $F s t=0.84$ at all loci examined). The total number of alleles per loci ranged from three to ten; the average number of alleles was 5.43. Examination of heterozygosity $\mathrm{He}$ ) revealed that these loci were moderately polymorphic. SSR2 showed the highest polymorphism, 0.83, and SSR7 showed the lowest, at 0.50 .
O. meridionalis group had four monomorphic loci, although Asian and New Guinean O. rufipogon groups showed polymorphism at all the loci. The number of alleles ranged from one to five in O. meridionalis, and from two to seven in Asian O. rufipogon. Averaged $\mathrm{He}$ scores were $0.47 \pm 0.25$ (mean \pm standard error) for Asian O. rufipogon, $0.57 \pm 0.06$ for New Guinean O. rufipogon, and $0.21 \pm 0.28$ for $O$. meridionalis. These basic data showed that the perennial $O$. rufipogon population tends to have higher diversity as does the New Guinean population. However, in the case of $O$. rufipogon, the accessions were collected in different Asian countries (Table 1). Thus, the $\mathrm{He}$ score would not reflect that in a natural population, but the general trend in a core collection.

a

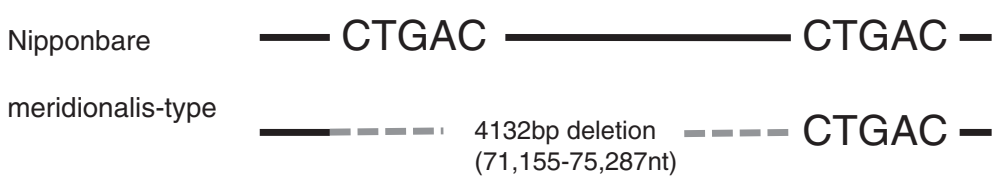

b

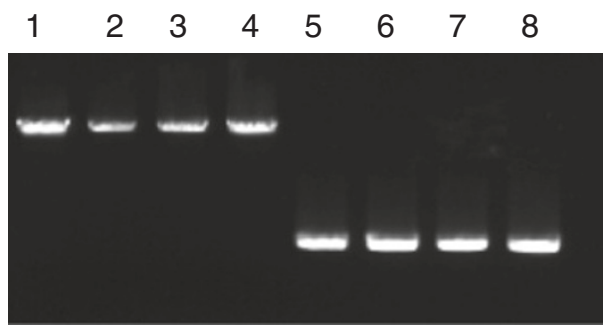

Figure 3 Deletion in mtDNA genome from nucleotides 71,155 to 75,287 which is found in 0 . meridionalis, three New Guinean O. rufipogon, two Australian O. rufipogon, and two perennial strains, Jpn1 and Jpn2. a. meridionalis-type mtDNA showed a deletion via a five base pair tandem duplication located at nucleotides 71,155-71,159 and 75,288-75,292. b. PCR amplification detected deletions in meridionalistype mtDNA. Lane 1 to 8 : Nipponbare, W106, W120, W137, W1299, W1300, Jpn1, and Jpn2. 
Table 4 Nuclear DNA INDEL genotypes among newly obtained accessions, O. rufipogon originated from Asia, Australia, and New Guinea, and 0 . merdinoalis

\begin{tabular}{|c|c|c|c|c|c|c|c|}
\hline \multirow[t]{2}{*}{ Site/Collection } & \multirow[t]{2}{*}{ Species/Accessions } & \multirow[t]{2}{*}{ No. of accessions } & \multicolumn{5}{|c|}{ Nuclear DNA INDEL genotypes } \\
\hline & & & INDEL5 & INDEL7 & INDEL8 & INDEL9 & INDEL10 \\
\hline Jpn1 & Australian perennial accessions & 3 & + & + & + & + & + \\
\hline Jpn2 & Australian perennial accessions & 5 & - & - & - & - & - \\
\hline Jpn3 & Australian perennial accessions & 5 & - & - & - & - & - \\
\hline Jpn4 & Australian perennial accessions & 3 & - & - & - & - & - \\
\hline Jpn10 & Australian perennial accessions & 3 & - & - & - & - & - \\
\hline Jpn11 & Australian perennial accessions & 3 & - & - & - & - & - \\
\hline Core collection & O. meridionalis & 18 & - & - & - & - & - \\
\hline \multirow[t]{2}{*}{ Core collection } & Asian O. rufipogon & 32 & + & + & + & + & + \\
\hline & Australian O. rufipogon W2078 & 2 & + & + & + & + & + \\
\hline Core collection & Australian O. rufipogon W2109 & 2 & + & + & + & + & + \\
\hline \multirow[t]{2}{*}{ Core collection } & NG O. rufipogon: W1230, W1236, W1238 & 3 & + & + & + & + & + \\
\hline & NG O. rufipogon: W1235, W1239 & 2 & - & - & - & - & - \\
\hline
\end{tabular}

Twenty-three Jpn accessions were clearly grouped by their nuclear DNA INDEL genotypes (Table 3). Thus, $\mathrm{Na}$ and $\mathrm{He}$ were calculated using two sets of new collections, Jpn1 group and Jpn2-11 group. The Jpn1 group was monomorphic at SSR1, SSR2, SSR5, and SSR.7. The Jpn211 group was monomorphic at six loci except for SSR2. A phylogenetic tree based on SSR genotypes was constructed using the neighbor-joining method (Figure 4). Population-based trees showed higher similarity between O. rufipogon and Jpn1. Accessions of O. rufipogon and Jpn1 were grouped in a single clade except for one accession, Jpn1-3, which was in a clade with most of the O. meridionalis accessions. Other Jpn accessions collected from Jpn2, Jpn4, Jpn10, and Jpn11 were in a clad with W2100, W2112, W2116, and all other O. meridionalis accessions originating from Queensland.

\section{Morphological traits}

Morphological traits relating to life history such as anther length, seed size and traits involving to seed productivity, were measured for the two perennial groups carrying the different nuclear genomes. The two perennials were compared with the typical annual accessions collected at the P27 site which was close to the Jpn1 site and defined as typical $O$. meridionalis types based on repetitive field observations.

Spikelet size varied hugely in Jpn2 compared to the others (Figure 5a). Distinct traits of Jpn2 were the large

Table 5 Fst, numbers of alleles ( $\mathrm{Na}$ ), and Heterozygosity in SSR markers among three groups, rufi (Asian O. rufipogon, $n=32$ ), meri (O. meridionalis, $n=18$ ), NG (New Guinean, $n=5$ ), AUS (Australian O. rufipogon, $n=5$ ) Jpn1 accessions $(\mathrm{n}=3$ ), and Jpn2-11 (accessions excluded Jpn1 site which obviously shared a similarity with 0 . rufipogon by nuclear INDELs, $\mathbf{n}=20$ ) with variation including all listed in Table 1

\begin{tabular}{|c|c|c|c|c|c|c|c|c|c|c|c|c|c|c|c|}
\hline \multirow[t]{2}{*}{ SSR locus } & \multirow[b]{2}{*}{ Fst } & \multicolumn{7}{|c|}{$N a(\mathrm{n}=)$} & \multicolumn{7}{|c|}{$\mathrm{He}$} \\
\hline & & Total & Asian rufi & meri & NG & Aus & Jpnl & Jpn2-11 & Total & Asian rufi & meri & NG & Aus & Jpn1 & Jpn2-11 \\
\hline SSR1 & 0.75 & 4 & 3 & 1 & 3 & 1 & 1 & 1 & 0.57 & 0.36 & 0.00 & 0.64 & 0.00 & 0.00 & 0.00 \\
\hline SSR2 & 0.21 & 10 & 6 & 5 & 4 & 2 & 1 & 2 & 0.83 & 0.71 & 0.68 & 0.70 & 0.38 & 0.00 & 0.32 \\
\hline SSR3 & 0.80 & 3 & 3 & 1 & 2 & 1 & 2 & 1 & 0.51 & 0.12 & 0.00 & 0.48 & 0.00 & 0.44 & 0.00 \\
\hline SSR5 & 0.54 & 5 & 4 & 1 & 4 & 1 & 1 & 1 & 0.60 & 0.66 & 0.00 & 0.72 & 0.00 & 0.00 & 0.00 \\
\hline SSR7 & 0.26 & 4 & 4 & 2 & 2 & 1 & 1 & 1 & 0.50 & 0.60 & 0.49 & 0.32 & 0.00 & 0.00 & 0.00 \\
\hline SSR9 & 0.50 & 9 & 7 & 1 & 3 & 1 & 3 & 1 & 0.66 & 0.67 & 0.00 & 0.64 & 0.00 & 0.67 & 0.00 \\
\hline SSR15 & 0.69 & 3 & 2 & 2 & 2 & & 2 & 1 & 0.63 & 0.17 & 0.28 & 0.48 & 0.00 & 0.44 & 0.00 \\
\hline No. of accessions & & 80 & 32 & 18 & 5 & 2 & 3 & 20 & & & & & & & \\
\hline Mean & 0.54 & 5.43 & 4.14 & 1.86 & 2.86 & 1.14 & 1.57 & 1.14 & 0.62 & 0.47 & 0.21 & 0.57 & 0.05 & 0.22 & 0.05 \\
\hline \pm SE & 0.09 & 1.09 & 0.67 & 0.55 & 0.34 & 0.14 & 0.30 & 0.14 & 0.04 & 0.09 & 0.11 & 0.06 & 0.05 & 0.11 & 0.05 \\
\hline
\end{tabular}

$\mathrm{Na}(\mathrm{n}=)$ : No. of alleles and number of accessions including each group. 


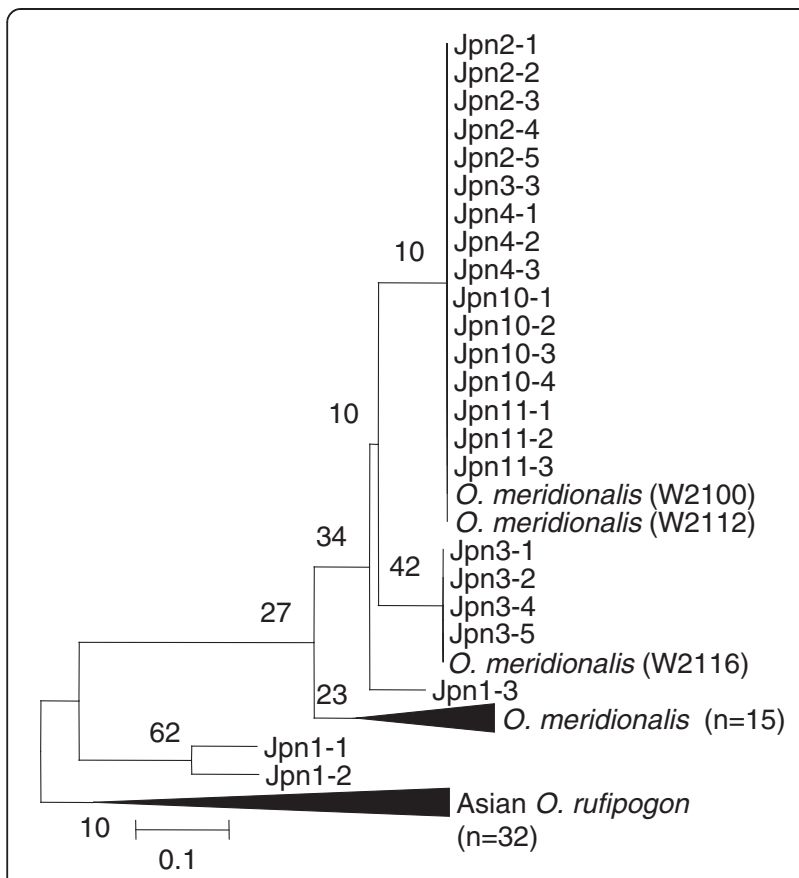

Figure 4 Phylogenetic tree by NJ method based on genetic distance measured with SSR genotypes. Compressed nodes shown as triangles were for $\mathrm{O}$. meridionalis and Asian O. rufipogon The former node included 15 accessions and another node included 32 accessions. Numbers indicate bootstrap values of (\%) with assessment of 1000 replicates. Scale was Nei's genetic distance (Nei et al. 1983).

spikelet size, large number of spikelets per panicle and awn size. The lemma size of Jpn2 was 9.14 \pm 0.53 (standard deviation) $\mathrm{mm}$ was significantly larger $(\mathrm{P}<0.01)$ than that of others. P27 carried the same organellar and nuclear genomes as the population at Jpn2 but had a relatively short lemma like Jpn1. This trait was regulated genetically, as plants grown under glass house conditions confirmed these differences.

Perennials tend to have longer anthers and lower seed productivity. The former trait is associated with the outcrossing rate and the latter trait may interact as a tradeoff with vegetative reproduction. As a species defining characteristic, O. rufipogon in Australia has been described as having an anther longer than $3 \mathrm{~mm}$. The population at the Jpn1 site had a significantly longer anthers, $5.02 \mathrm{~mm}$ in length under field conditions compared to those of O. meridionalis and populations at the Jpn2 site (Figure $5 \mathrm{~b}$ and c, Table 6). These relative relationships were shown to be genetic by confirmation when grown under glass house conditions.

Awn length in Jpn2 was $10.23 \pm 0.55 \mathrm{~cm}$ but those of Jpn1 and P27 were $7.60 \pm 0.86 \mathrm{~cm}$ and $6.76 \pm 0.84 \mathrm{~cm}$, respectively. We could not measure awns under glass house condition because bagging of panicles so as to not to disperse the seeds from spikelets restricted the development of the awns. The most distinctive trait for P27 was panicle size. P27 individuals carried the longest panicles even though they produced the smallest number of spikelets under field condition.

The number of spikelets per panicle for Jpn2 was $70.0 \pm$ 14.4 under field conditions (Figure $5 \mathrm{~d}$ ). This was significantly more than that of Jpn1 $(\mathrm{P}<0.05)$. This trend may be independent of factors such as the nitrogen in the soil because the difference was reconfirmed with plants grown under glass house condition (Table 6). Individuals at the Jpn1 site had a reduced number of spikelets, when they were grown under glass house condition. This mainly resulted from a reduction of secondary spikelets. It may be not have been warm enough to generate secondary spikelets, as we observed at heading in October in Japan. The number of spikelets was increased on the first rachis both in Jpn1 and Jpn2. Fertilization may be affected only by the number of spikelets on the first rachis.

\section{Discussion}

\section{Nomenclature of $O$. meridionalis}

Generally, annual species, O. meridionalis, and perennial species, O. rufipogon have been known in Australia as the Oryza species belonging to AA genome (Henry et al. 2010, Vaughan 1994, Waters et al. 2012). However, in Australia we have not observed an annual form of $O$. rufipogon, which is sometimes referred to as $O$. nivara (Sharma 2003). Only O. meridionalis is found as an annual species. In this report, we clearly identified a novel perennial form very close to O. meridionalis and distinct from $O$. rufipogon.

One of the obvious morphological differences between $O$. meridionalis relative to O. rufipogon is anther length. It has been noted that $O$. meridionalis should have an anther length of less than 1.5-2.5 mm whereas O. rufipogon should have a longer anther at 3-7.4 mm (Waters et al. 2012). Our observations revealed that only the plants at Jpn1 had relatively longer anthers (Table 6). Individuals from the Jpn2 and Jpn3 sites showed anther lengths shorter than those from Jpn1, in August 2010. The short anther was not influenced by environmental factors because glass house data indicated the traits were confirmed repetitively in the case of Jpn1 and Jpn2 accessions. In spite of these characteristics, individuals at the Jpn2 and Jpn3 sites survived throughout the dry season. Their resource allocation allowed nodes to generate shoots and roots in water (Additional file 3: Figure S3). Thus, the criterion of anther length is not applicable to classification of Australian wild rice based upon life history traits. Other traits, lemma size, number of spikelets per panicle, and panicle length were different between P27 accessions (O. meridionalis) and Jpn2. Generation of a second rachis in Jpn2 resulted in a higher number of spikelets although they did have a shorter panicle length. Thus, the novel accessions are quite divergent to 


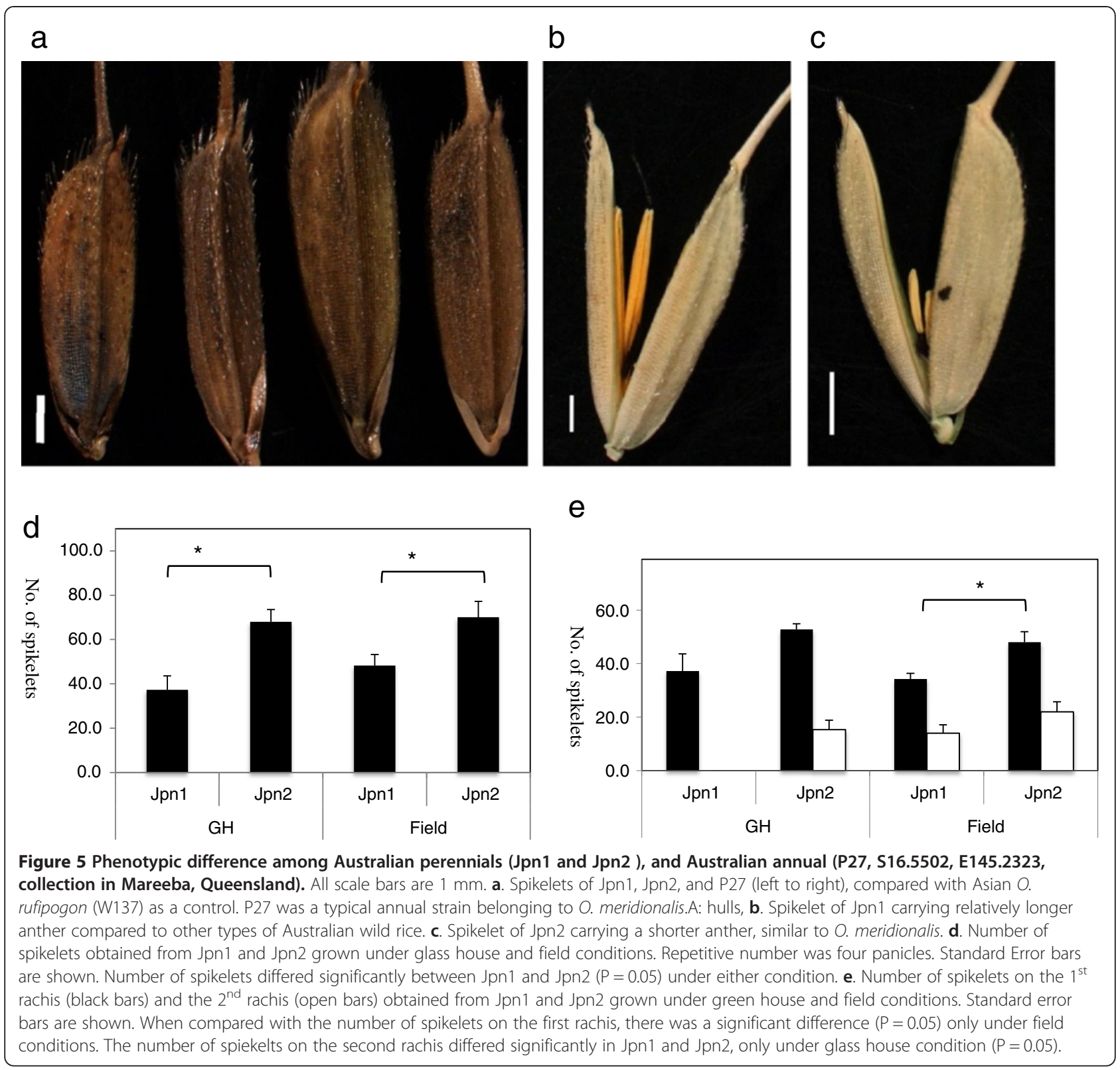

O. meridionalis. It infers that the novel perennial type could be a new species. Cross fertility is now being confirmed.

All de novo accessions in Australia were classifiable as O. meridionalis based on organellar genomes (Table 3). The sequences at both rpl16 and INDEL genotype in ctDNA revealed diagnostic plastid types, which could be further supported by whole-genome sequence data for the plastid genome of $O$. meridionalis (Waters et al. 2012). This trend was also seen in mtDNA (Figure 3). Simple structural change was fixed in Australia among not only all accessions but also Australian accessions in the core collection. Asian accessions did not show any changes at the site. Nuclear INDEL genotypes clearly distinguished O. meridionalis from Asian O. rufipogon and $O$. sativa. Five accessions of $O$. rufipogon originating in New Guinea were quite distinct from Asian accessions. Because they had various combinations of nuclear-plastid/ mitochondrial types even they had been collected at a single swamp (Katayama 1968). Although these accessions have been defined as O. rufipogon, the primarily species definitions were $O$. perennis and $O$. sativa var. spontanea which had been used as annual wild rice. Based on SSR genotypes, three were included in a clade with O. rufipogon. One of the three accession, W1238 also carried rufipogon-type nuclear INDELs but meridionalis-type organelle genomes like Jpn1 accessions (Table 3). Two carried meridinoalis-type nuclear and organella genomes. 
Table 6 Morphological diffferences between the two types of perennial

\begin{tabular}{|c|c|c|c|c|c|c|c|c|}
\hline \multirow[b]{2}{*}{ Traits } & \multicolumn{3}{|c|}{ GH } & \multicolumn{5}{|c|}{ Field } \\
\hline & Jpn1 & Jpn2 & t-test $^{\#}$ & Jpn1 & Jpn2 & t-test & P27 & t-test against to Jpn1 \\
\hline \multicolumn{9}{|c|}{ Anther length $(n=5)$} \\
\hline Mean (mm) & 4.03 & 1.68 & $* *$ & 5.02 & 2.05 & $* *$ & 1.76 & $* *$ \\
\hline SD & 0.22 & 0.27 & & 0.17 & 0.10 & & 0.24 & \\
\hline \multicolumn{9}{|c|}{ Lemma length $(n=4)$} \\
\hline Mean (mm) & 7.18 & 8.96 & $* *$ & 7.44 & 9.14 & ** & 7.19 & ns \\
\hline SD & 0.36 & 0.10 & & 0.38 & 0.53 & & 0.57 & \\
\hline \multicolumn{9}{|c|}{ Panicle length $(n=4)$} \\
\hline Mean $(\mathrm{cm})$ & 15.15 & 16.38 & ns & 23.13 & 19.68 & ns & 26.30 & ns \\
\hline SD & 3.04 & 2.17 & & 2.14 & 1.90 & & 4.80 & \\
\hline \multicolumn{9}{|c|}{ No. of spikelets per panicle $(n=4)$} \\
\hline Mean & 37.3 & 68.0 & * & 48.3 & 70.0 & $* *$ & 46.3 & ns \\
\hline SD & 12.7 & 11.0 & & 10.0 & 14.4 & & 3.4 & \\
\hline \multicolumn{9}{|c|}{ Awn length $(n=20)$} \\
\hline Mean $(\mathrm{cm})$ & - & - & & 7.60 & 10.23 & $* *$ & 6.76 & * \\
\hline SD & & & & 0.86 & 0.55 & & 0.84 & \\
\hline
\end{tabular}

Seeds and panicles of Jpn1, Jpn 2, and P27 were collected in the field. Seeds of Jpn1 and Jpn2 were grown under glass house (GH) condition and harvested to measure traits. Repetitive counts ( $n$ ) were average and the mean and standard deviation were presented as mean and SD.

\#: t-test was used to test differences against Jpn1. Significant levels were indicated as $*(P=0.05)$ and ${ }^{* *}(P=0.01)$.

They might belong to O. meridinoalis. Additional accessions along with ecological information for New Guinea are needed to evaluate their genetic characteristics in detail. All the new Australian perennial accessions carried meridionalis-type organellar genomes. However, there are alternative types of perennials based on their nuclear genotypes.

\section{Genetic divergence among species}

Genetic similarity in nuclear genomes was estimated by INDEL analysis and SSR genotyping (Tables 4 and 5). Annuals were dead at the time of collection and had already scattered their seeds on the ground (Figure 1c). In contrast, all perennials survived through rainy season (Figure 1d and g) to dry season (Figure 1f and i). Repetitive observations at the same sites confirmed their life history traits. Those individuals surviving in the dry season were regarded as perennials, and morphologically different from O. meridionalis. However, all accessions collected from the perennial populations shared the same meridionalis-type organellar genomes.

Our genetic data for the perennial AA genome accessions revealed distinct characteristics that have never been found in Asia when compared with the core collection examined in this study. At the molecular level based on ctDNA, all accessions shared DNA polymorphisms with $O$. meridionalis. On the other hand, the nuclear genotypes clearly divided the accessions into the Jpn1 type and an alternative type. The Jpn1 type was included in a clade with Asian O. rufipogon, but the alternative was in a clade with O. meridionalis (Figure 5). Phylogenetic trees based on SSR genotypes showed that a Jpn1-3 accession was close to $O$. meridionalis in the clade and also to Jpn2 type perennial accessions. In contrast, five nuclear INDEL genotypes clearly indicated that the Jpn1-3 accession at Jpn1 site was defined as belonging to the Asian O. rufipogon group (Table 4). This discrepancy would be due to hyper-variation essential to nuclear SSR repeats. Seven SSR loci were not enough to obtain a phylogenetic tree with high bootstrap values on each node.

\section{Evolutionary pathway for generation of Australian perennials}

These results reveal that there are two types of perennials in Australia, r-type and m-type. Then, when did the two perennial types evolve? The question remains to be resolved.

The following possible models can be envisaged:

1) A second migration model: parallel evolution with a second migration of the r-type perennial.

2) Hybrid species (the r-type perennial) and parallel evolution.

3) Hybrid species followed by divergence.

The second migration model presumes that the rtype perennial might have originated from an ancestor that evolved in Asia, which was also a contributor to the Asian O. rufipogon gene pool because our recent 
crossing experiment has shown that Jpn1 can generate fertile progeny in crosses with Asian wild rice (data in preparation). O. meridionalis may have been in Australia long before the r-type. Populations related to the ancestor of the r-type perennial may now be extinct in Asia, or have evolved to become modern $O$. rufipogon because we have not found the Australian r-type in Asian genetic resources when we have screened the core collection and other material. Independently from the r-type perennial, the m-type perennial could have been the result of adaptive divergence from a common ancestor to O. meridionalis to occupy a particular niche where annuals could not fit. Our preliminary data on reproductive barriers indicates that Jpn2 does not produce much fertile pollen in hybrids with O. rufipogon $(<10 \%)$ or O. meridionalis $(<20-40 \%)$. This pollen fertility produced no seeds in glass house. A reproductive barrier may have developed between the annual and perennial populations. However, because they share an ancestral lineage, they have similar morphological and molecular signatures.

Hybrid species with parallel evolution is the second option. Hybrid species might have been generated by a spontaneous cross between Asian O. rufipogon and $O$. meridionalis. This could explain the origin of the r-type perennial, but the m-type perennial might be the result of adaptive convergence, as in the above option. A possible date for the introgression of Asian O. rufipogon is 50,000 to 70,000 years ago when an ancient continent, Sunda, was located close to Sahul because of a lowered sea level at that time. The rufipogon-type nuclear genotypes with an meridionalis-type organella genomes might have predominated under the prevailing environmental conditions. Hybrid fertility between Asian O. rufipogon and O. meridionalis is as low as $10 \%$ (Chu et al. 1969). Once hybrid species occur in nature, subsequent backcrosses may be required to create fertile progeny. From the current $r$-type perennial genome constitution it is presumed that pollination from Asian O. rufipogon to O.meridionalis occurred. This would have yielded m-type organellar genomes and Asian O. rufipogon nuclear genomes in a distinct species. Perennials prefer to outcross and retain their genetic diversity to a greater degree than annuals and annuals prefer to self-pollinate (Oka 1988). Once hybrids were created, this plant may have been a highly competitive perennial (with some heterosis) that continued to interbreed with the O. rufipogon-like population in the same unidirectional way. When we screened more individuals in Australia, no individual carrying the rufipogon-type organellar genomes was found. We are unable to explain why there was no perennial with an rufipogon-type organelle genomes because currently there is no evidence that the organelle genomes of $O$. meridionalis confers any advantage over the Asian O. rufipogon type. We would also expect heterozygotes or heterogeneous genotypes at some loci in this case. However, we have not yet detected such perennials.

In the last model, both the r-type and m-type perennials shared the same incipient progenitor as a spontaneous hybrid between Asian O. rufipogon and O. meridionalis. If so, we would expect heterozygous or heterogeneous genotypes at some loci or mixtures of plastid types within populations. However, all of the accessions examined carried a rufipogon-type or a meridionalis-type nuclear genome with an m-type organellar genome. We have not found any Jpn2-type perennials in the Northern Territory. The rufipogon-type genomes spread in northern Australia from Northern Territory to Queensland because previous specimens collected in the Northern Territory such as W2078 and also in Queensland as W2109, belong to the rufipogon-type perennial group. The hybridization would need to have occurred sufficiently long ago for the genome constituents to stabilize, to spread over this wide range, and gain complete fertility. This does not explain why the meridionalis-type organellar genomes became predominant in both lineages and we do not have any evidence for this event.

The current distribution of Australian O. rufipogon is quite broad, as is that of O. meridionalis (Henry et al. 2010). Therefore the presumed parents must have arrived quite a long time ago in each case. Thus, the recent cultivated rice species, O. sativa, cannot be the parent of these species. Nevertheless, O. sativa is a domesticated species related to O. rufipogon, and exchange of their genes by spontaneous crosses resulted in weedy rice (Oka and Chang 1959). There are a few records indicating that domesticated O. sativa was briefly cultivated in these areas of Australia, although cultivation did not persist because of bird attacks (Waters et al. 2012). Only the Jpn1 perennial accessions share similarity of nuclear genotypes with Asian O. rufipogon and O. sativa. Jpn1 is close to Cairns city in distance, where Asians (especially Chinese and Japanese) immigrated in the late 19th century. However, two hundred years might not have been long enough for wild rice to have stabilized after natural hybridization without any sign of domestication traits. Furthermore, perennial types have also been found in Northern Territory and Queensland to carry the Asian O. rufipogon-type nuclear genome by estimation of pSINE1 insertion (Xu et al. 2005). Our data also showed that it carried the meridionalistype organellar genomes with the rufipogon-type nuclear genome. Thus, perennials with the rufipogontype nuclear genome have dispersed in unrestricted areas of northern Australia. They cannot be attributed to recent and regional introduction of particular kinds of Asian cultivated rice. It is therefore unlikely that Jpn1 is the progeny of weedy rice resulting from crossing between Australian wild rice and Asian cultivars. The morphological appearance of the Australian populations 
suggests that they are not the progeny of cultivated rice. If Australian wild rice had been crossed with domesticated rice, specific characteristics would have been generated as weedy rice such as non-shuttering trait, white grain, high sterility in seed setting, or thick stem (Ishikawa et al. 2002, 2005). Such characteristics have never been found in Jpn1 site. Thus, Jpn1 is not a remnant of cultivars like weedy rice. Birds might act as a vector to bring seeds to northern Australia. In addition, the appearance of Jpn2 is not similar to that of Asian O. rufipogon from Asia. We were able to detect highly sterile populations in Weipa, northern Queensland, where annual and perennial individuals were found together. They are possibly progeny of recent hybridization between Jpn1 type and O. meridionalis because of their higher sterility based on the field observation.

Due to genetic distance and preliminary results of hybridization tests, the second migration or hybridization models seem to provide a possible explanation. The former model, however, would have more probability because we have not found remnant of hybridization events at the molecular level. Thus, we concluded that our second migration model would be appropriate to explain the nature of divergence of Oryza species in Australia. In order to draw a firm conclusion, more data on genome constituents compared to known species, divergence time, and evidence of reproductive relationships are needed. The two alternative perennials, the Jpn 1 and Jpn2 groups, are probably best considered as new and distinct species that diverged a long time ago.

\section{Genetic reservoir}

Wild rice belonging to the AA genome is a genetic reservoir for use in improving cultivars so that they can be more resistant to biotic and abiotic stress. O. meridionalis has been used to establish chromosomal segment introgression lines (Yoshimura et al. 2010). Such introgressions have been used to introduce useful genes from wild AA genomes, and sometimes generate plants of different ploidy or with different genomes (Khush 1997). For O. australzensis, genes conferring insect resistance, such as Bph10 and Bph18, and fungus resistance, such as Pi40, have been reported (Ishii et al. 1994, Jena et al. 2006, Jeung et al. 2007). O. meridionalis and other species in Australia have not been exploited significantly in rice breeding. Because of the limited collections of this material, it has not been possible to evaluate genetic polymorphism for annual populations of $O$. meridionalis or perennial populations such as the Jpn1 and Jpn2 types in their natural habitat. Sympatric habitats, where annual and perennial populations are growing together, are common in north Queensland. A potential hybrid population has been found in Lakeland. Although they may have low fertility, perennials tend to outcross because of their preference for resource allocation. Such potential hybrids or relatives would be good candidates for improving domesticated species. Bridging breeding can be used to efficiently introduce alien segments of genomes to modern varieties. Australian perennial wild rice populations will soon be evaluated more precisely for their genetic characteristics under in situ conditions. Intermediate type would be found because of the probable hybridization event in Weipa. In addition to that, artificial crossing experiment will show us how intermediate type behaves in nature or conditioned environment. Extra efforts to ensure conservation of the native habitat of these species have been suggested in order to facilitate continued research on these valuable resources under in situ conditions.

\section{Conclusion}

Analysis of current accessions clearly indicated that there are two distinct types of Australian perennials.Both of them differed genetically from Asian O. rufipogon. One lineage, $\mathrm{m}$-type is closely related to O. meridionalis and another, r-tpe to Asian O. rufipogon. The m-type was presumed to have evolved by divergence from $O$. meridionalis based on molecular nature. It is the first accession which has never been found in the former collection. The m-type shared morphological similarity to some extent but differed in spikelet size. Shorter anther of the m-type and O. meridionalis is a key character of annual species tended to self-pollinate. However, its life history observed in nature was not annual. It is becoming differentiated as a perennial species in Australia indicating that it represents a new gene pool. The r-type apparently derived from Asian O. rufipogon, possibly arrived in Australia later, because of its nuclear genotypes sharing higher similarity to Asian O. rufipogon. Maternal genomes suggested r-type, m-type, and O. meridinoalisi shared a single lineage. It will give us a clue to understand rice evolution and expansion into a new continent.

\section{Methods \\ Plant materials}

Wild rice was collected in Australia with permission from the Queensland government, under the EcoAccess program. We developed these collections as de novo resources, which can be accessed repeatedly from the same site with accurate GPS data, allowing us to reconfirm their life cycles. Successive observations were carried out from 2009 until 2011, and the life history traits of plants at the collection sites were reconfirmed year by year. The field research was supported by overseas scientific research funds (JSPS) and collaborative research with 
Queensland Herbarium and QAAFI, University of Queensland. Observations of the ecological habitat and life cycle of each population in April 2008, August 2009, and September 2009 were used to determine whether each population was annual or perennial. In total, 23 perennial individuals were collected at six sites (Table 1, Figure 1a). Annuals were observed at the Jpn6, Jpn7, Jpn8, Jpn9, and P27 sites. Jpn6 was a typical annual site, as shown in Figure 1a and 1b. In the dry season, the fields dried out completely and individual plants dispersed their seeds. Jpn1 and Jpn2 were typical perennial sites, and individual plants survived in a swamp (Jpn1) or pond (Jpn2) where constant water supply was available (Figure 1c to $\mathrm{f}$ ). Due to the objectives of this study, only perennial individuals were studied further. One individual per site was pressed and dried to donate as a herbarium specimen to the Queensland herbarium. DNA from the 23 individuals was extracted from dried leaves and some of the DNA materials were stocked in the DNA bank of Southern Cross University. Jpn1 and Jpn2 accessions as representatives of alternative perennials were characterized for anther length, awn size, spikelet size, number of spikelets, and panicle size. Both of the perennials were replanted in pots using a general nursery procedure for cultivated rice under glass house condition at Kagoshima University with natural day length. These plants were also examined for the above morphological traits. Data was obtained for single individuals. The length of anthers in single spikelets was measured. Anther length and lemma size were measured with a NIKON digital sight.

Thirty-two Asian O. rufipogon, two Australian O. rufipogon, five New Guinean O. rufipogon, and 18 O. meridionalis accessions from the NIG core collection (hereafter core collection) established at the National Institute of Genetics, Mishima, Japan, were used as controls (Nonomura et al. 2010). The DNA samples were kindly supplied by the National Institute of Genetics. Phenotypic characteristics and phylogentic relationships among some of these strains have been described by Morishima (1969).

\section{Identification of plastid type from the rpl16 sequences and INDELs in ctDNA and mtDNA}

Sequences of rpl16 were used for comparison of maternal origin. Two pairs of primers (rpl16 primers forward and reverse) shown in Table 2 were used to amplify a whole region of rpl16 gene. Amplified fragments were purified with QIAquick PCR purification kit (QIAGEN co., Japan). Then, these fragments were prepared for sequencing by BigDye Terminator v3.1 Cycle Sequencing kit (Applied Biosystems co., Japan) to obtain sequences with ABI310 sequencer. Additional primers, 457r (5'- CTCTTTGTTATTCCTTGAAATTTG -3') and 500f (5'- TTTTTGGAAGCTCCATTGCGAG -3'), 1095r (5'- TGTTTACGAAATCTGG TTCTTTT -3'), and 1kbf (5'-ATGAGAAGAAACTCTCA
TGTCC-3') were used to obtain inner sequences of the rpl16 gene. Single insertions of 5 bp at nucleotides 7998/ 7999 , or double insertions of $5 \mathrm{bp}$ at nucleotides 7998/ 7999 and nucleotides $8197 / 8198$, have been reported in flanking sequences of chloroplast encoding ORF, ORF100 (Takahashi et al. 2008). These insertions were detected only in $O$. meridionalis. The core collection and new accessions were primarily confirmed by sequencing. A pair of primers, ORF100-INDE were used to amplify the sequencing templates. Another pair of primers, ctDNA336 was used to amplify the region for comparison by electrophoresis as ORF100-INDEL (Figure 2). All ctDNA markers were amplified with NEB Taq using the buffer supplied by the manufacturer (NEB co., Japan). The mitochondrial DNA of O. meridionalis has aligned to the Nipponbare reference sequence (AB076665 and AB076666) by using whole genome data reported (Waters et al. 2012). A large unaligned region was presumed to be a deletion fragment. The deletion of the mtDNA INDEL was amplified. The amplification was carried out under the following conditions: $98^{\circ} \mathrm{C}$ for $3 \mathrm{~min}, 35 \mathrm{cycles}$ of $98^{\circ} \mathrm{C}$ for $10 \mathrm{sec}, 64^{\circ} \mathrm{C}$ for $30 \mathrm{sec}$, and then $72^{\circ} \mathrm{C}$ for $5 \mathrm{~min}$, followed by $72^{\circ} \mathrm{C}$ for $5 \mathrm{~min}$ as an extension step with iProof Taq polymerase using the buffer supplied (Bio-Rad Co., USA).

\section{INDEL and SSR markers}

Partial genomic sequence data for 21 indica cultivars, 18 tropical japonica cultivars, 32 accessions of O. rufipogon, one from $O$. merdionalis (IRGI101148), and one from $O$. barthii (IRGC104119) were used to develop nuclear DNA INDEL markers, with sequence information which had been kindly provided from published data (Molina et al. 2011). Five sequenced fragments were used to design nuclear DNA INDEL markers, as listed in Table 2, distinguishing fragments that originated from $O$. meridionalis as deletion types (Figure 4). INDEL10 was recognized as a DNA transposable element related to Stowaway (Bureau and Wessler 1994). These fragments shared 98\% homology with each other. There was no insertion among the 18 accessions of $O$. meridionalis we used, including INDEL10 and others. In addition, all accessions of Asian O. rufipogon carried insertions.

Seven SSR loci were also designed based on sequence information from the above materials. All primer sequences are shown in Table 2. Ampliqon-Taq (Ampliqon Co., Denmark) was used for amplification with the manufacturer's supplied buffer. PCR conditions were $94^{\circ} \mathrm{C}$ for $3 \mathrm{~min}, 30$ rounds of $94^{\circ} \mathrm{C}$ for $10 \mathrm{sec}, 55^{\circ} \mathrm{C}$ for $30 \mathrm{sec}$, and $72^{\circ} \mathrm{C}$ for $30 \mathrm{sec}$, followed by $72^{\circ} \mathrm{C}$ for $5 \mathrm{~min}$ for postheating. Amplified products were genotyped using 6\% denatured sequencing gels with a general silver staining method based on the SILVER SEQUENCE ${ }^{\mathrm{TM}}$ DNA Sequencing System (Promega Co., USA). 


\section{Data analysis}

The GenAlEx 6.2 software package (Peakall and Smouse 2006) was used for evaluating genetic variations in loci and populations, including the number of different alleles per locus $(\mathrm{Na})$, Fst, observed heterozygosity $(\mathrm{Ho})$, and expected heterozygosity $(\mathrm{He})$. Dendrograms were constructed using the neighbor-joining method based on Nei's unbiased genetic distances using the Populations 1.2.30 beta2 program (http://bioinformatics.org/populations/). Bootstrap values were assessed with 1000 replicates. All dendrograms were drawn by TreeExplorer (Tamura et al. 2011).

\section{Additional files}

Additional file 1: Figure S1. Polymorphism characterizing the chloroplast genome of Oceania wild rice. a. SNP found in the rp/16 gene of the ctDNA genome of Asian O. rufipogon, Australia O. rufipogon, and $O$. meridionalis. T-A substitution (676 nt) and C insertion between 770 and $771 \mathrm{nt}$ in the $1^{\text {st }}$ intron, C-T substitutions at $1295 \mathrm{nt}$ and $1406 \mathrm{nt}$. b. Phylogenetic tree created by the NJ method based on using rp/16 sequences of $O$. sativa cV. Nipponbare, O. rufipogon, and O. meridionalis. The substitution rate is indicated as in the bar below.

Additional file 2: Figure S2. Alignment of nuclear DNA INDEL markers. Panels a to e show sequences of INDEL5, 6, 7, 8, 9, and 10 with corresponding sequences in Jpn1, Jpn2, Jpn3, P27, and W1300. Except for INDEL10, they did not show any resemblance to transposable elements. INDEL10 was a Stowaway transposable element. Insertion types at the five INDEL loci, were only found among Asian species, $O$. sativa and $O$. rufipogon.

Additional file 3: Figure S3. Jpn2 individuals inhabits through dry season. a. Jpn2 site in August, 2011, b.young shoot and roots emerging out from nodes.

\section{Competing interests}

The author declares that they have no competing interests.

\section{Author's contributions}

MA, YK, KT, KI, IN, TS, Y-IS, and RI organized and worked to collect new accessions in Australia and evaluate their life history. JF and MP aligned DNA sequences to set up INDEL markers specified species identification. DC and BS contributed to preparing, evaluating, and managing herbarium specimens. DW, RH, KO, RI provided NGS data to identify SNP and deletions. YH sequenced rpl16 gene. SSR genotyping was conducted by YK. RI performed population genetics and INDEL genotyping. All authors contributed to the manuscript.

\section{Acknowledgements}

The field research was supported by overseas scientific research funds (JSPS) as a Grant-in-aid B (Overseas project, No.21405016 and 25304021). This study was partly supported by the Japan Society for the Promotion of Science (JSPS) Asian CORE Program entitled "Cooperative Research and Educational Center for Important Plant Genetic Resources in East Asia". We also dedicated this paper to Dr. Morishima who encouraged authors to test Australian wild rice.

\section{Author details}

${ }^{1}$ Faculty of Agriculture and Life Science, Hirosaki University, Hirosaki, Aomori 036-8561, Japan. ${ }^{2}$ Science of Cryobiosystem, The United Graduate School of Agriculture Sciences, Iwate University, Morioka, Iwate 020-8550, Japan.

${ }^{3}$ Faculty of Humanities, Hirosaki University, Hirosaki, Aomori 036-8561, Japan. ${ }^{4}$ Faculty of Agriculture, Kagoshima University, Korimoto, Kagoshima 890-0065, Japan. ${ }^{5}$ Department of Biology and Center for Genomics and Systems Biology, New York University, New York, NY 10003, USA. ${ }^{6}$ Graduate School of Horticulture, Chiba University, Matsudo 648, Matsudo, Chiba 0271-8510,
Japan. ${ }^{7}$ Research Institute for Humanity and Nature, Kyoto 603-8047, Japan. ${ }^{8}$ Graduate School of Life Science, Tohoku University, Sendai, Miyagi 980-8577, Japan. ${ }^{9}$ Australian Tropical Herbarium, James Cook University, Cairns, Queensland 6811, Australia. ${ }^{10}$ Queensland Herbarium, Brisbane Botanic Gardens Mt Coot-tha, Brisbane, Queensland 4066, Australia. ${ }^{11}$ Southern Cross Plant Science, Southern Cross University, Lismore, NSW 2480, Australia. ${ }^{12}$ Queensland Alliance for Agriculture and Food Innovation, University of Queensland, Brisbane, Queensland 4072, Australia.

Received: 9 April 2013 Accepted: 9 August 2013

Published: 28 October 2013

\section{References}

Akimoto M, Shimamoto Y, Morishima H (1998) Population genetic structure of wild rice Oryza. Mol Eco 7:1371-1381

Augee M, Fox M (2012) Biology of Australia and New Zealand. Pearson Education Australia, Sydney NSW, Australia

Bellwood P (2005) The origins and dispersals of agriculture: some operational considerations. In: First Farmers. The Origins of Agricultural Societies. Blackwell Publishing Ltd, Massachusetts, pp 12-43

Bureau TE, Wessler SR (1994) Stowaway: a new family of inverted repeat elements associated with the genes of both monocotyledonous and dicotyledonous plants. Plant Cell 6:907-916

Chang TT (1976) The origin, evolution, cultivation, dissemination, and diversification of Asian and African rice. Euphytica 25:425-441

Cheng C, Tsuchimoto S, Ohtsubo H, Ohtsubo E (2002) Evolutionary relationships among rice species with AA genome based on SINE insertion analysis. Genes Genet Syst 77:323-334

Chu YE, Morisima H, Oka HI (1969) Reproductive barriers distributed in cultivated rice species and their wild relative. Jpn J Genet 44:207-223

Ge S, Sang T, Lu BR, Hong DY (1999) Phylogeny of rice genomes with emphasis on origins of allotetraploid species. PNAS 96:14400-14405

Henry RJ, Rice N, Waters DLE, Kasem S, Ishikawa R, Hao Y, Dillon S, Crayn D, Wing R, Vaughan D (2010) Oryza: Utility and conservation. Rice 3:235-241

Ishii T, Brar DS, Nultani DS, Khush GS (1994) Molecular tagging of genes or brown planthopper resistance and earliness introgression from Oryza australiensis into cultivated rice, O. sativa. Genome 37:217-221

Ishikawa R, Yamanaka S, Kanyavong K, Fukuta Y, Sato Y-I, Tang L, Sato T (2002) Genetic resources of primitive upland rice in Laos. Econ Botany 56:192-197

Ishikawa R, Toki N, Imai K, Sato Y-I, Yamagishi H, Shimamoto Y, Ueno K, Morishima H, Sato T (2005) Origin of weedy rice grown in Bhutan and the force of genetic diversity. Genet Resour Crop Evol 52:395-403

Jena KK, Jeung JU, Lee JH, Choi HC, Brar DS (2006) High-resolution mapping of a new brown plant hopper $(\mathrm{BPH})$ resistance gene, Bph18 (t), and markerassisted selection for $\mathrm{BPH}$ resistance in rice (Oryza sativa $\mathrm{L}$ ). Theor Appl Genet 112:288-297

Jeung JU, Kim BR, Cho YC, Han SS, Moon HP, Lee YT, Jena KK (2007) A novel gene, Pi40 (t), linked to the DNA markers derived from NBS-LRR motifs confers broad spectrum of blast resistance in rice. Thoer Appl Genet 115:1163-1177

Katayama TC (1968) Scientific rport on the rice-collection-trip to the Philipines, New Guinea, Borneo and Java. Memoirs of the Faculty of Agriculture, Kagoshima University 6:89-134

Khush GS (1997) Origin, dispersal, cultivation and variaton of rice. Plant Mol Biol 35:25-34

Lu BR (1999) First record of the wild rice Oryza meridionalis in Indonesia. IRRI Newslt 24:28

Molina J, Sikora M, Garud N, Flowers JM, Rubinstein S, Reynolds A, Huang P, Jackson S, Schaal BA, Bustamante CD, Boyko AR, Purugganan MD (2011) Molecular evidence for a single evolutionary origin of domesticated rice. PNAS 108:8351-8356

Morishima H (1969) Phenetic similarity and phylogenetic relationships among strains of Oryza perennis, estimated by methods of numerical taxonomy. Evolution 23:429-443

Morishima H, Sano Y, Oka HI (1984) Differentiation of perennial and annual types due to habitat conditions in the wild rice Oryza perennis. Plant Syst Evol 144:119-135

Nei M, Tajima F, Tateno Y (1983) Accuracy of estimated phylogenetic trees from molecular data. II. Gene frequency data. J Mol Evol 19:153-70. 
Ng NQ, Chang TT, Williams JT, Hawkes JG (1981) Morphological studies of Asian rice and its related wild species and the recognition of a new Australian taxon. Biol Jour Linnean Society 16:303-313

Nonomura K-I, Morishima H, Miyabayashi T, Yamaki S, Eiguchi M, Kubo T, Kurata N (2010) The wild Oryza collection in National BioResource Project (NBRP) of Japan: history, biodiversity and utility. Breed Sci 60:502-508

Oka HI (1974) Experimental studies on the origin of cultivated rice. Genetics 78:475-486

Oka HI (1988) Origin of cultivated rice. Japan scientific societies press, Tokyo, Elsevier Amsterdam

Oka HI, Chang WT (1959) The impact of cultivation on populations of wild rice. Oryza sativa f. spontanea. Phyton 13:105-117

Oka HI, Morishima H (1967) Variations in the breeding systems of a wild rice, Oryza perennis. Evol 21:249-258

Peakall R, Smouse PE (2006) GENALEX 6: genetic analysis in Excel: population genetic software for teaching and research. Mol Ecol Notes 6:288-295

Sano Y, Morishima H (1982) Variation in resources allocation and adaptive strategy of a wild rice, Oryza perennis Moench. Bot Gaz 143:518-523

Second G (1985) Evolutionary relationships in the Sativa group of Oryza based on isozyme data. Genet Sel Evol 17:89-114

Sharma SD (2003) Species of genus. In: Nanda JS, Sharma SD (eds) Science publishers, Monograph on Genus Oryza Inc, New Hampshire, USA, pp 73-111

Takahashi H, Sato Y-I, Nakamura I (2008) Evolutionary analysis of two plastid DNA sequences in cultivated and wild species of Oryza. Breed Sci 58:225-233

Tamura K, Peterson D, Peterson N, Stecher G, Nei M, Kumar S (2011) MEGA5: molecular evolutionary genetics analysis using maximum likelihood, evolutionary distance, and maximum parsimony methods. Mol Biol and Evol 28:2731-2739

Tang L, Zou XH, Achoundong G, Potgieter C, Second G, Xhang DY, Ge S (2010) Phylogeny and biogeography of the rice tribe (Oryzae); evidence from combined analysis of 20 chloroplast fragments. Mol Phyl Evol 54:266-277

Vaughan D (1994) A: the wild relatives of rice -a genetic resources handbook pp64. IRRI, Manila Philippines

Wallace AR (1880) Island life, or the phenomena and causes of insular faunas and floras. Macmillan, London

Waters D, Nock CJ, Ishikawa R, Rice N, Henry RJ (2012) Chloroplast genome sequence confirms distinctness of Australian and Asian wild rice. Eco and Evol 2:211-217

Xu JH, Kurta N, Akimoto M, Ohtsubo H, Ohtsubo E (2005) Identification and characterization of Australian wild strains of Oryza meridionalis and Oryza rufipogon by SINE insertion polymorphism. Genes Genet Syst 80:129-134

Yoshimura A, Nagayama H, Sobrizal C, Kurakazu T, Sanchez PL, Doi K, Yamagata Y, Yasui H (2010) Introgression lines of rice (Oryza sativa L.) carrying a donor genome from the wild species. O glumaepatula Steud and O meridionalis $\mathrm{Ng}$ Breed Sci 60:597-603

Zhu Q, Ge S (2005) Phylogenetic relationships among A-genome species of the genus Oryza revealed by intron sequences of four nuclear genes. New Phyt 167:249-265

doi:10.1186/1939-8433-6-26

Cite this article as: Sotowa et al:: Molecular relationships between Australian annual wild rice, Oryza meridionalis, and two related perennial forms. Rice 2013 6:26.

\section{Submit your manuscript to a SpringerOpen ${ }^{\odot}$ journal and benefit from:}

- Convenient online submission

- Rigorous peer review

- Immediate publication on acceptance

- Open access: articles freely available online

- High visibility within the field

- Retaining the copyright to your article

Submit your next manuscript at $>$ springeropen.com 